\title{
Darmstadt Rotor No. 2, III: Experimental Analysis of an Aft-Swept Axial Transonic Compressor Stage
}

\author{
Stephan Kablitz, Jörg Bergner, and Dietmar K. Hennecke \\ Darmstadt University of Technology, Darmstadt, Germany \\ Manfred Beversdorff and Richard Schodl \\ DLR Cologne, Cologne, Germany
}

\begin{abstract}
At Darmstadt University of Technology (Darmstadt, Germany), the Department of Gas Turbines and Flight Propulsion operates a single-stage transonic compressor test stand. Its main purpose is to provide a database for the validation of computational fluid dynamics codes. In addition, it serves as a testbed for new materials and also for the development of new measurement techniques. After setting up the test rig with a baseline rotor (Rotor No. 1), a titanium bladed disk with conventional radially stacked blade sections, a new rotor (Rotor No. 2) was designed, with the addition of considerable amounts of aft sweep and backward lean. The new rotor's flow field and mechanical properties were investigated by using various measurement techniques, including a laser-2-focus setup.
\end{abstract}

Keywords CFRP, L2F, Lean, Sweep, Transonic compressor

In the early 1990s at Darmstadt University of Technology (Darmstadt, Germany), a single transonic compressor stage was brought into operation. The first rotor investigated was a titanium bladed disk (blisk). Rotor No. 1 was extensively tested by various measurement techniques. The rotor blade's passage was

Received 25 June 2002; accepted 1 July 2002.

The Rotor 2 project was supported by the German Ministry of Education and Research under contract 20T9402 and by MTU Aero Engines, Munich, Germany.

The authors thank G. Schulze and C. Blaha for their ongoing support for the Darmstadt test rig. M. Zielinski and G. Ziller helped to optimize the Darmstadt rig for optical blade vibration measurements and provided the relevant data for this paper. H. Barth worked on the evaluation software for the Laser-2-Focus raw data and provided the images of blade passage flow.

Address correspondence to Jörg Bergner, Darmstadt University of Technology, Petersenstrasse 30, Darmstadt, D-64287, Germany. E-mail: bergner@gfa.tu-darmstadt.de investigated by making three-dimensional laser-2-focus (L2F) measurements (Blaha et al., 1997).

Following recent publications concerning the influence of sweep and lean on transonic compressor blading (Denton et al., 1999, Hah et al., 1998 and Wadia et al., 1998), a new rotor was designed in cooperation with MTU Aero Engines (Munich, Germany). Rotor No. 2 was meant to be as similar as possible to Rotor No. 1 so it would be possible to isolate the influence of sweep and lean. (Aerodynamic intent and design restrictions are discussed in Parts I and II of this article.) After an unsuccessful attempt in 1998, Rotor No. 2 was brought into operation in 2000. Its performance and flow field were investigated in great detail and some of the most interesting aspects are described in this article.

\section{DARMSTADT'S TRANSONIC COMPRESSOR}

This section briefly describes the test rig and the conventional instrumentation used to determine speed lines and efficiency. The two first figures show a general sketch of the Darmstadt compressor test rig (Fig. 1) and a cross-sectional drawing of the compressor stage (Fig. 2).

Inlet stagnation pressure and temperature were taken in the settling chamber in front of a bell mouth. At the inlet, the wall's static pressure was measured, using a calibrated nozzle, to determine the mass flow. Pressure losses in the inlet duct were accounted for by an experimentally determined loss coefficient. The downstream flow conditions were taken from fixed totalpressure and total-temperature probe rakes located on the bearing support struts behind the stator, while the stator is traversed circumferentially. The shaft speed, power, and torque were measured by a Torquemeter Inc. measuring device located between the $800 \mathrm{~kW}$ DC drive and the compressor. The aerodynamic characteristics of Rotor No. 2 and an impression of the blading are given in Table 1 and Figure 3.

The experimental data gathered in Darmstadt over the past years has been used for the validation of computational fluid 


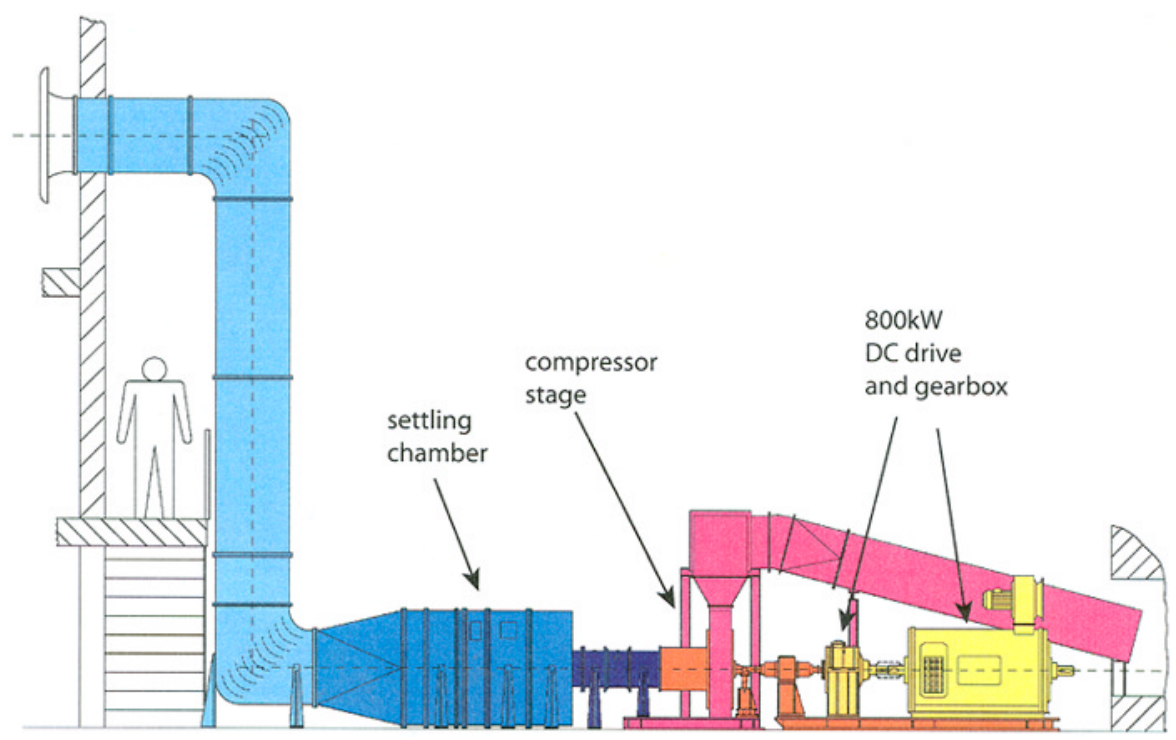

FIGURE 1

Sketch of the installation.

dynamics (CFD) codes, and on the basis of the experience with Rotor No. 1, new design ideas were incorporated into the design of Rotor No. 2, which is an aft-swept blading manufactured of carbon-fiber reinforced plastic (CFRP). Rotor designs with forward-swept blades are under consideration for the future, to further investigate the influence of sweep and lean on the transonic flow field.

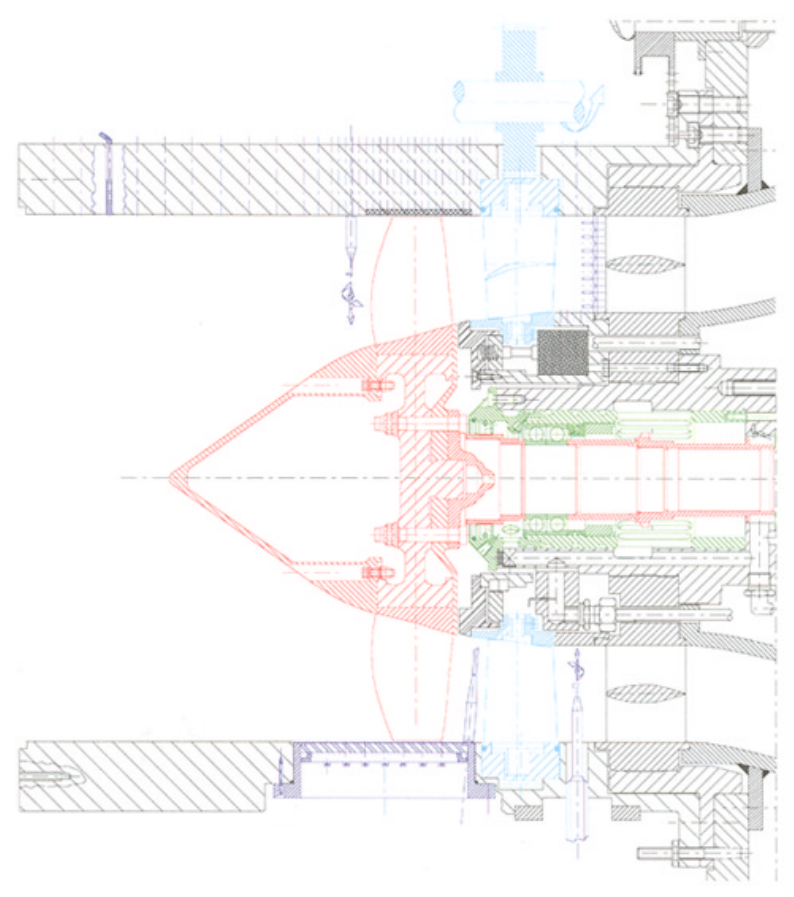

FIGURE 2

Cross section of the compressor.

\section{OPTICAL BLADE OSCILLATION MEASUREMENTS}

Before measurements of aerodynamic data were taken, the mechanical integrity of the rotor had to be tested. This was accomplished by taking optical blade oscillation measurements, which were conducted by MTU Aero Engines (Munich, Germany) on site. The measurement system used optical sensors mounted above the blade tips at various axial positions that measured the time differences between the passing of each blade. This setup was presented by Zielinski and Ziller (2000).

One set of results enabled the determination of the blade amplitudes and the frequencies of synchronous oscillations at the investigated axial positions. For the most prominent resonance (here, the first flexing mode, excited by the third engine order), the amplitudes of each blade are shown at three different throttle settings (Fig. 4). Although the various throttle settings have

\section{TABLE 1}

Characteristics of Rotor No. 2 at design point

\begin{tabular}{ll}
\hline Shaft speed & $20,000 \mathrm{rpm}$ \\
Shaft power & $580 \mathrm{~kW}$ \\
Mass flow rate & $16 \mathrm{~kg} / \mathrm{sec}$ \\
Number of blades & 16 \\
Outer diameter & $0.38 \mathrm{~m}$ \\
Tip speed & $400 \mathrm{~m} / \mathrm{sec}$ \\
Hub-to-tip ratio & 0.51 \\
Relative inlet Mach number at tip & 1.35 \\
Relative inlet Mach number at hub & 0.7 \\
Isentropic efficiency & 0.84 \\
Pressure ratio & 1.43 \\
\hline
\end{tabular}




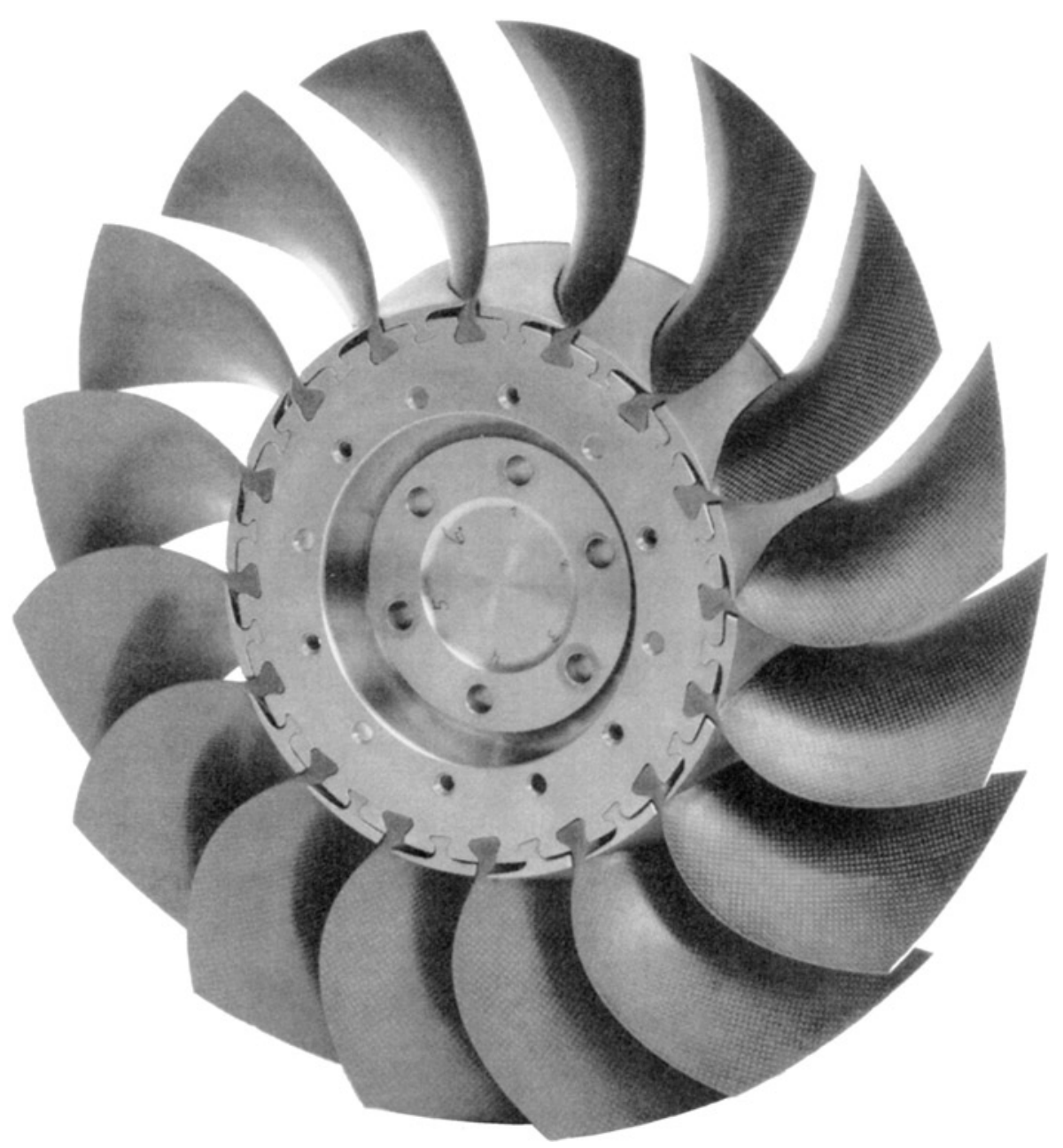

FIGURE 3

CFRP Rotor No. 2.

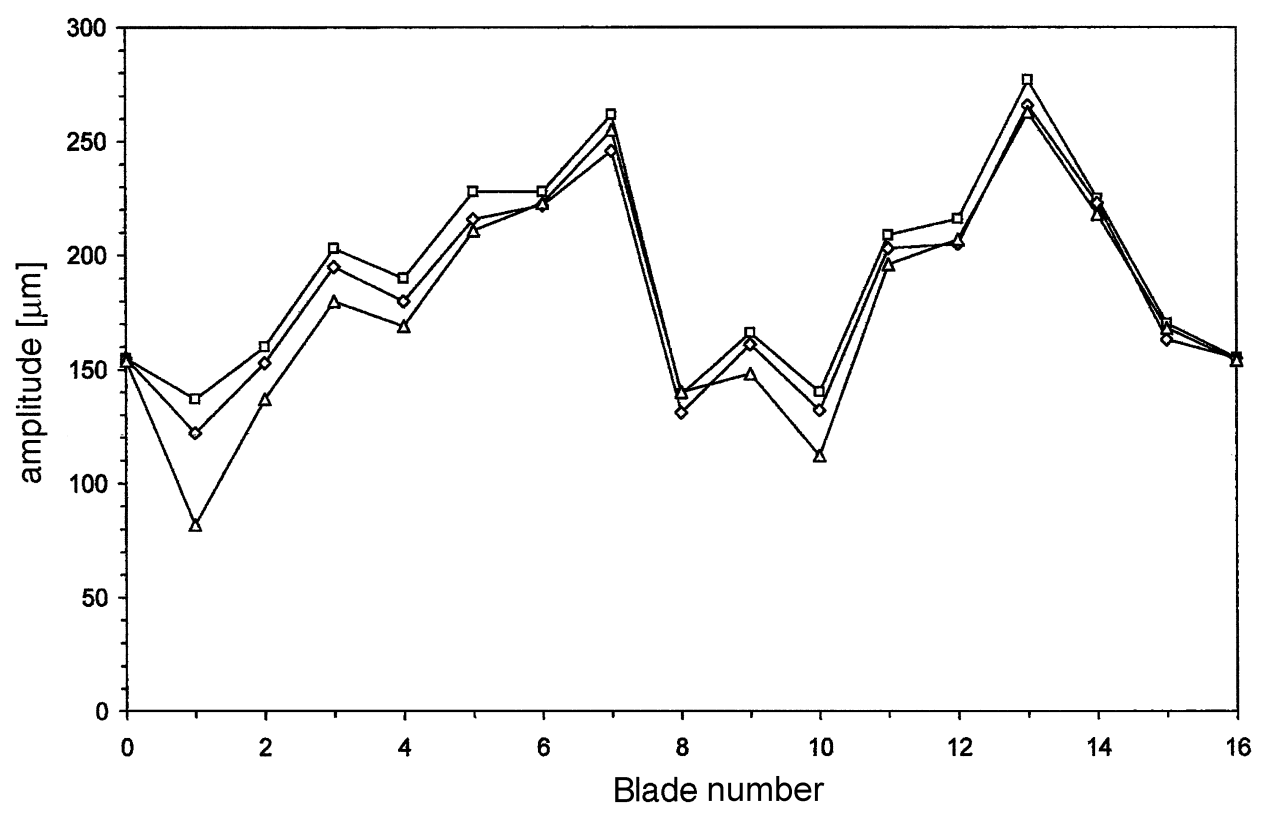

FIGURE 4

Blade amplitudes@IF/3rd Engine Order (EO). 


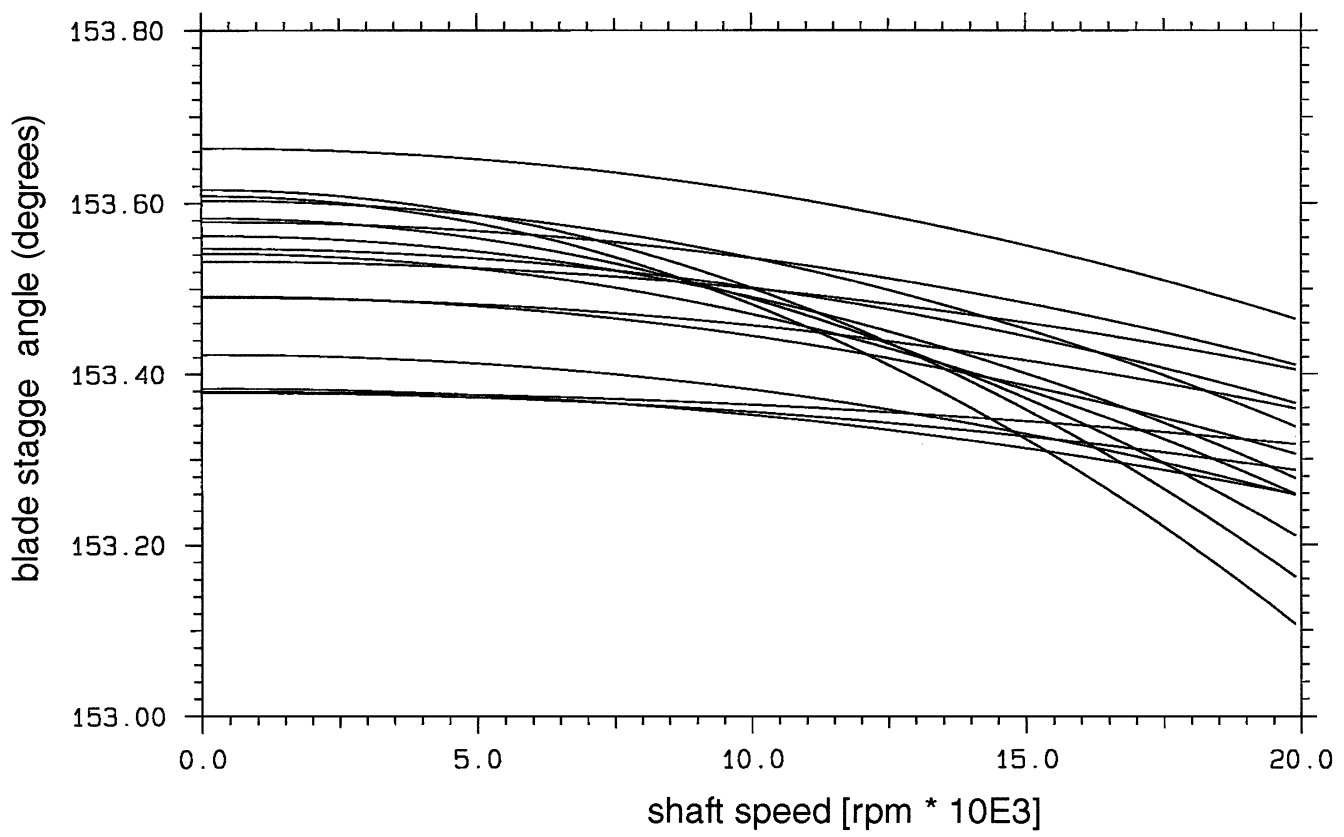

FIGURE 5

Untwist with increasing shaft speed.

no significant influence, the differences between the individual blades were clearly visible.

Another possible evaluation yields untwist of the blades. By comparing the measurements at positions near Leading Edge and near Trailing Edge it is possible to quantify the untwist of the blade tip with increasing shaft speed. Results are shown for each of the 16 blades in Figure 5.

The untwist is, in general, very low due to the light weight of the CFRP blades (the density of the material is only one third that of titanium), which creates low centrifugal forces. It was also found, in this evaluation, that each individual blade showed a great difference from the others in the amount of its untwist; some scarcely untwisted at all. This phenomenon must be attributed to the manual manufacturing process, which results in slight variations in the fabric's orientation from blade to blade. This leads to the conclusion that in the future, when CFRP is used in compressor blades, untwist can be actively influenced by modification of the fiber or fabric orientation.

\section{PERFORMANCE MAP MEASUREMENTS}

Measurements of speed lines were performed by recently upgraded Pitot-type total-pressure and total-temperature rakes mounted on the five struts downstream of the stator (Fig. 6).

Complementing the 11 Pitot-type total-pressure probes were two static-pressure taps located at the same axial positions to gather static-pressure information at the hub and casing. By traversing the stator upstream of the rakes in increments of 5\% stator pitch, the stator exit plane was resolved with 20 positions pitchwise and 13 probe locations from hub to tip, yielding 260 single pressure values.

To determine the total pressure ratio, the data was first averaged circumferentially. For averaging in the radial direction, the pressures were weighted according to local mass flow. Isentropic efficiency was calculated by comparing compressor work input into the flow taken from pressure measurements with work input at the shaft, which is measured by the torquemeter.

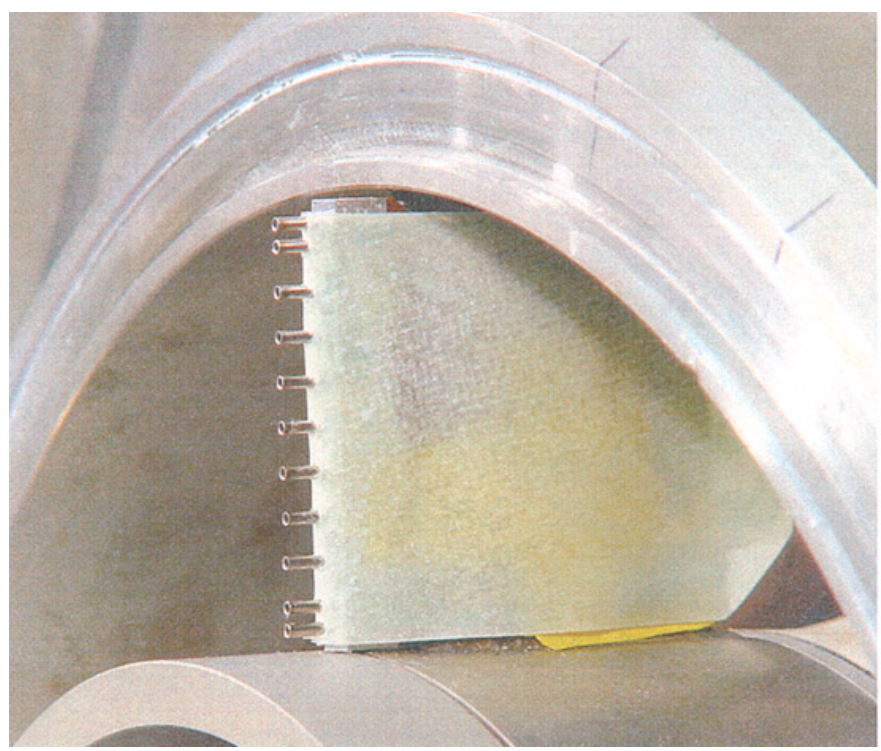

FIGURE 6

Total temperature rake. 

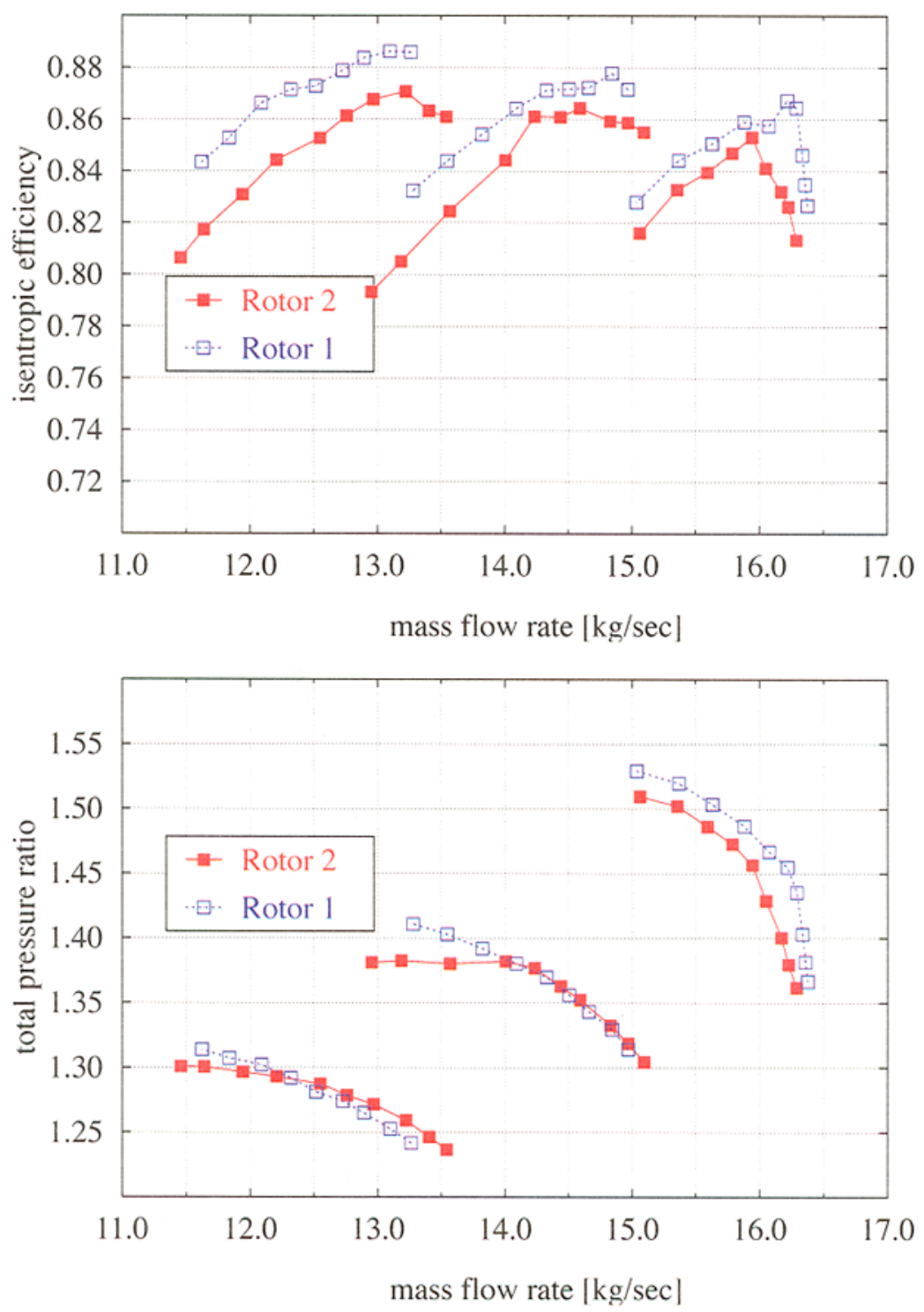

FIGURE 7

Speedlines at $80 \%, 90 \%$ and $100 \%$ speed.

Total temperature measurements at the stator exit have proven to provide good general information about radial distributions of efficiency, but quantitatively precise averaged results are too difficult to obtain because of the rather long time needed for temperature measurements.

The data aquisition took $4 \mathrm{~min}$ for each operating point. Measurement uncertainties were calculated according to the methods suggested by Saravanamuttoo (1990). For a 95\% confidence level (U95) at 100\% speed and peak efficiency operating point, this yields:

mass flow rate $\pm 1.1 \%$ pressure ratio $\pm 0.5 \%$ isentropic efficiency $\pm 1.4 \%$.
On the basis of the speed lines (Fig. 7), it was obvious that the intention of adding sweep and lean to the baseline design while retaining the overall characteristics of the stage could not be fulfilled.

The decrease in efficiency and performance was unsatisfying. However, contrary to the results reported by others (Hah et al., 1998; Wadia et al., 1998), a significant decrease in the stall margin could not be detected. Compared to the baseline rotor, Rotor No. 2 delivered slightly lower pressure ratios but showed a similar operating range.

In addition, the transition into unstable operation did not occur as sharply as was observed with Rotor No. 1; the unswept rotor reacted to a slight decrease of the throttle area by an immediate rotating stall, which was clearly audible, and by significant 
reduction in shaft power. In Rotor No. 2, the transition was smooth, the noise level building up slowly while still delivering almost the same pressure rise. (More detailed measurements of stall inceptions were taken and will be discussed in Part IV of this article.)

From spanwise distributions of pressure at the stator exit (shown in Figure 8a, b, and c) some undesired defects become visible near the hub region, and they seem to cause the lower speed lines of Rotor No. 2, as compared to Rotor No. 1.
Rotor No. 2 seemed to have trouble putting enough work into the flow. Overall, the defect, in direct comparison to Rotor No. 1 , was decreasing with lower mass flow rates and concentrates in the lower part of the annulus.

From general considerations regarding sweep and lean (Denton et al., 1999), it can be expected that relative to the baseline of Rotor No. 1, a mass-flow redistribution toward the hub would be associated with the added aft sweep of Rotor No. 2, leading to a lower incidence in the airfoil planes near the hub.
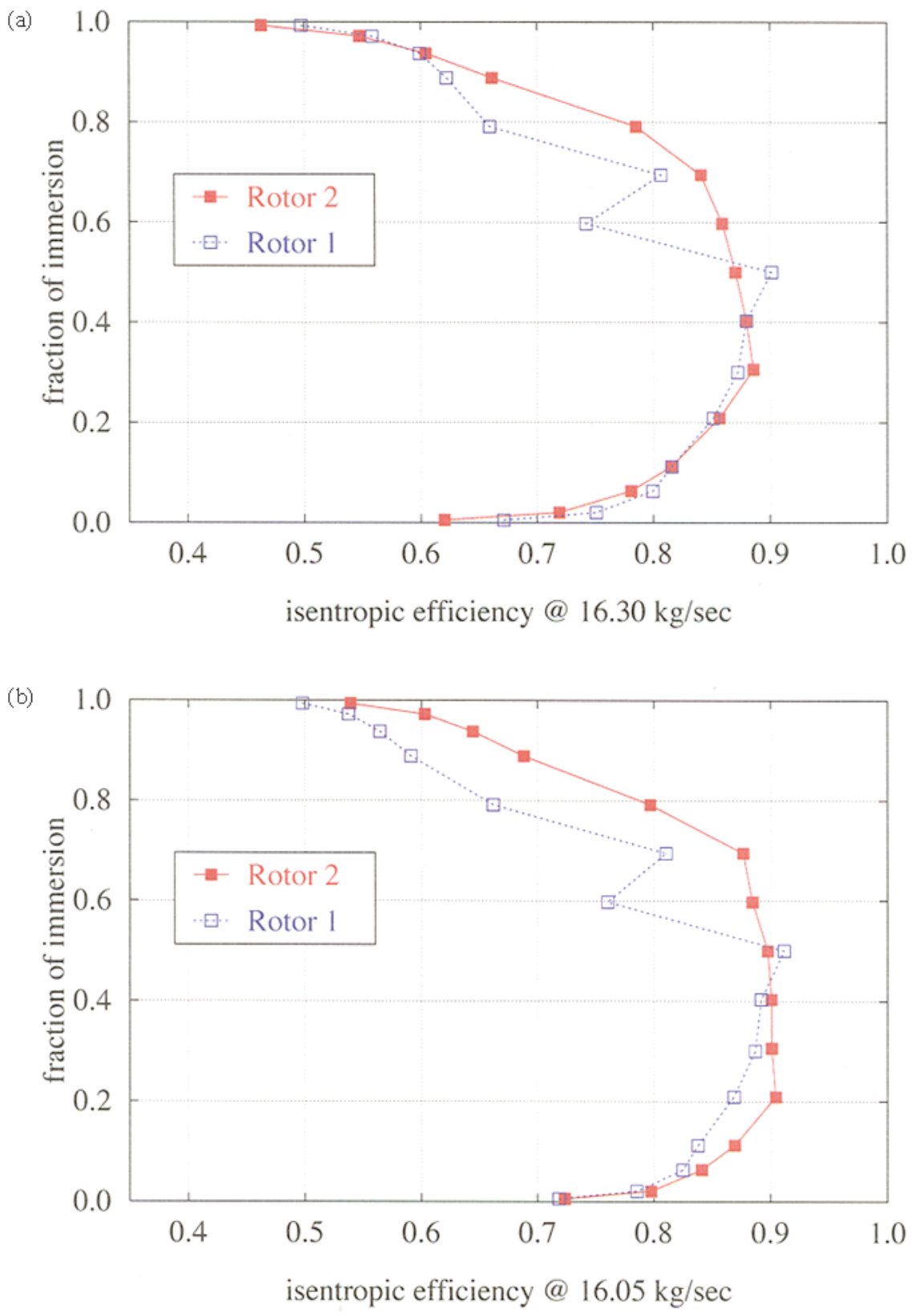

FIGURE 8

Radial distribution of pressure ratio. (Continued) 


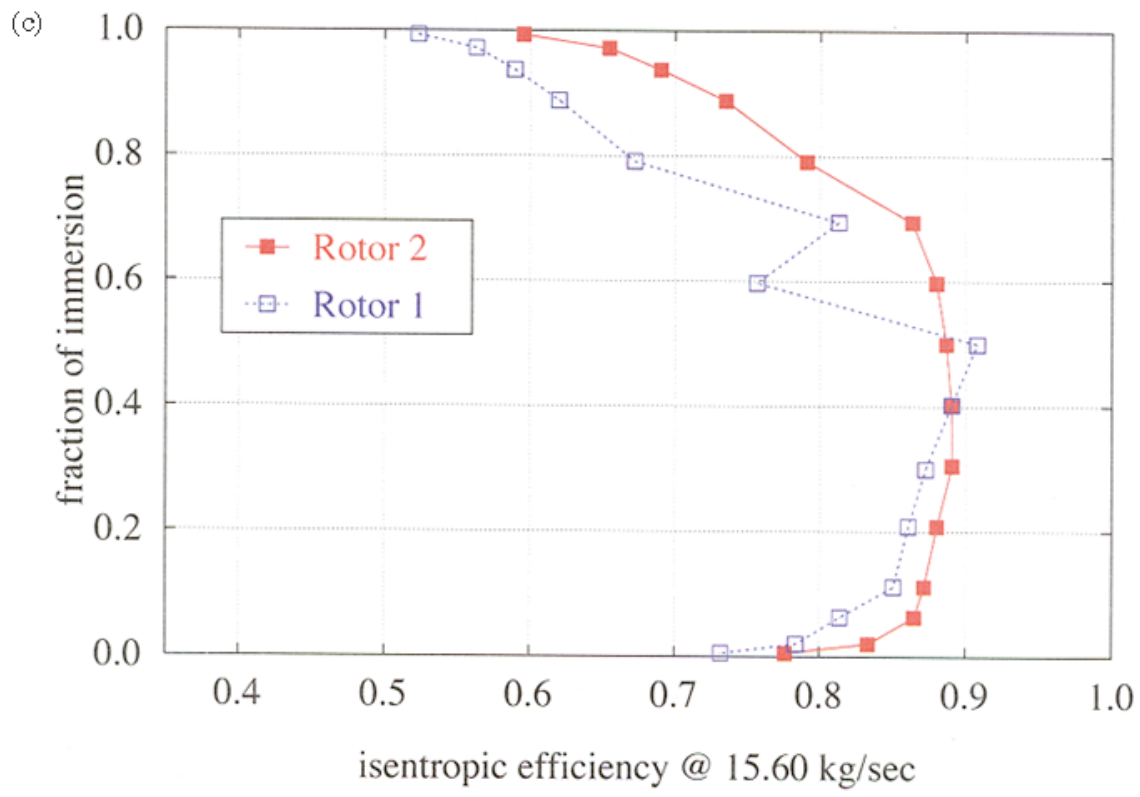

FIGURE 8

(Continued) Radial distribution of pressure ratio.

To further investigate these phenomena, the flow field inside the rotor blade's passage was investigated.

\section{LASER-2-FOCUS MEASUREMENTS}

The L2F measurement campaign was conducted in cooperation with DLR Cologne (Cologne, Germany) which developed the three-dimensional L2F system that had also been used previously to investigate Rotor No. 1. The experimental setup is shown in Figure 9.

Access to the annulus is quite restricted, so L2F is the method of choice among the various Particle Image Velocimetry systems.

Because of the long duration of L2F experiments (the presented data required $80 \mathrm{hr}$ of operating time at $100 \%$ speed),

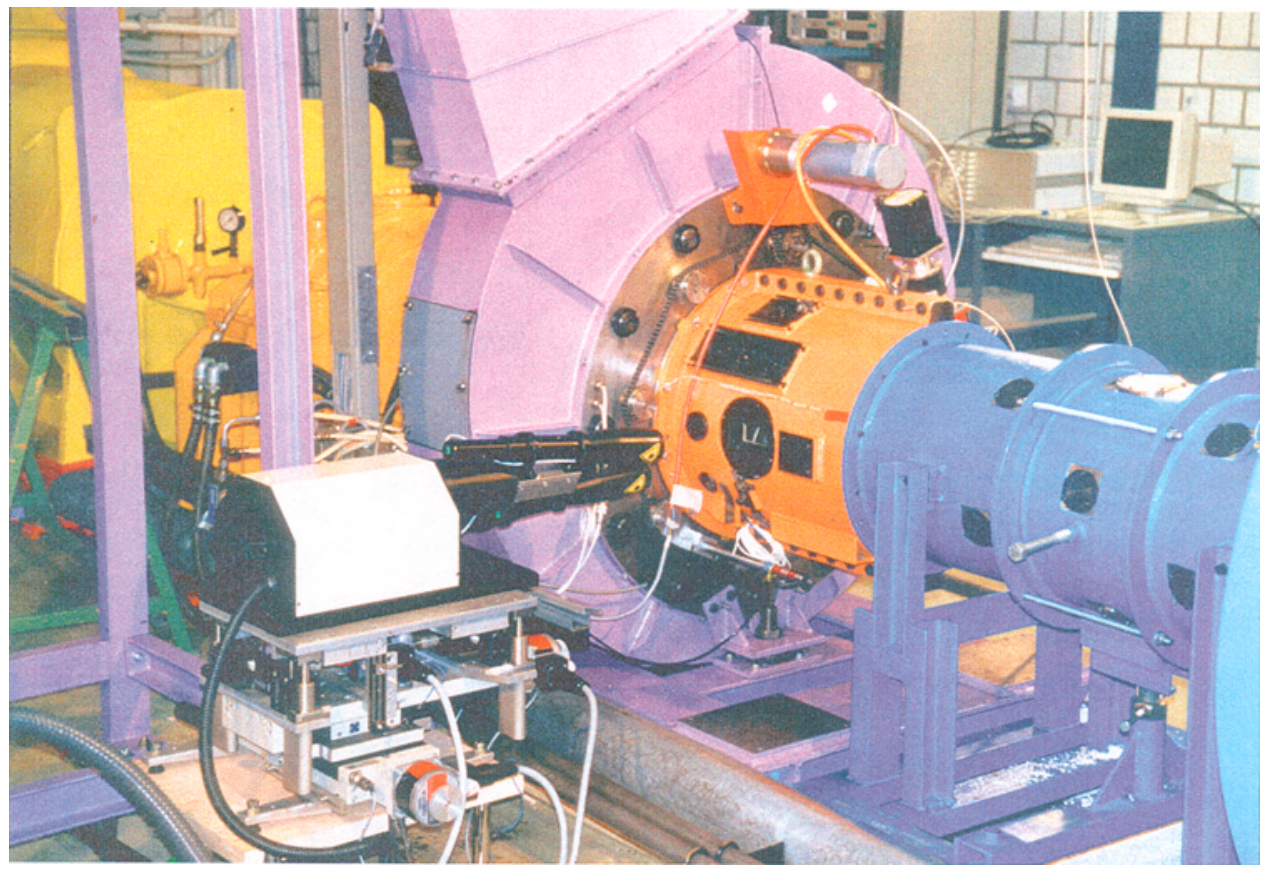

FIGURE 9

L2F setup with optical head. 


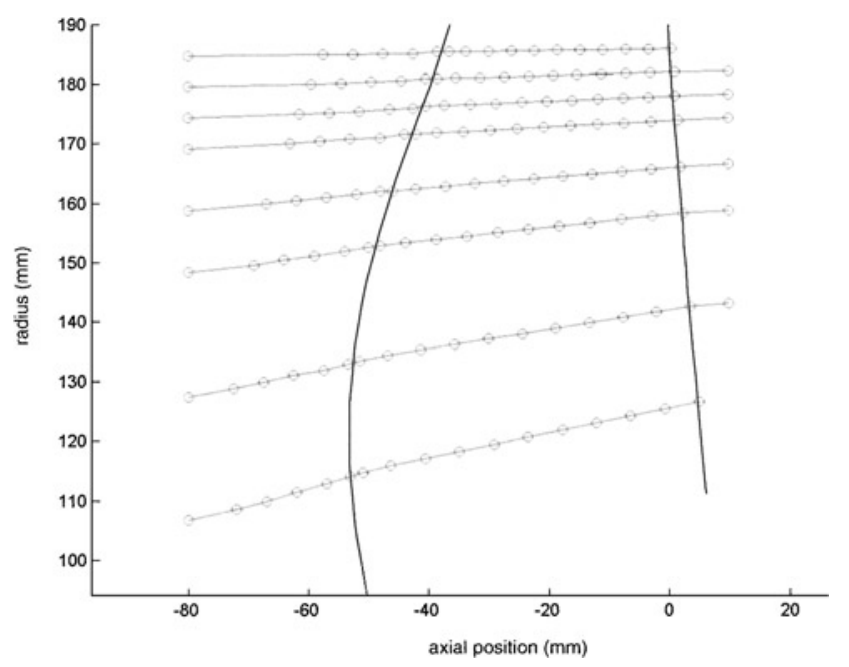

FIGURE 10

L2F measurement grid in S2 plane.

the flow-field investigation was concentrated on design speed and three different operating conditions. The chosen mass flows were to represent near-choke, peak efficiency, and near-stall conditions. The behavior close to instability was not investigated at that time, so a safe distance from stall of the compressor was maintained for safety reasons. For the mass flows $15.5 \mathrm{~kg} / \mathrm{sec}$, $16.0 \mathrm{~kg} / \mathrm{sec}$ (the design point), and $16.3 \mathrm{~kg} / \mathrm{sec}$, the grid shown in Figure 10 was scanned. Pitchwise, the grid was resolved in 16 points, discarding the ones that were either occupied or shadowed by the blades. Higher pitchwise resolution is possible, but it would increase measurement time beyond reasonable limits.
Spanwise, the grid was placed on levels of constant relative radius $(20,40,60,70,80,85,90$, and $95 \%)$ because the pretest interest was in the shock structure near the region of the tip. Figures 11, 12, and 13 show the rotor flow in three S1 planes of interest, all at a shaft speed of 20,000 rpm. Axial coordinates are given in millimeters relative to the rotor's trailing edge at the tip.

L2F is not capable of resolving blade-surface pressure distributions. However, to get an idea of the conditions, the measurements that were nearest the rotor's suction side were plotted onto the S2 projection of the blade for the design point in Figure 14. The information from the suction side clearly showed a double shock system reaching down almost to the hub. In the tip region, it could be observed that the shock seemed to enter the endwall in a nonperpendicular direction. This seemed contradictory, because in theory, there can be no radial velocity at the endwall, and no reflection of the shock was shown. However, in the investigation by Hah and colleagues (1998), a similar shock structure in the tip region during a near-stall state was reported for Rotor No. 8 which was tested in the Compressor Aero Research Lab (Air Force) test rig.

For a better understanding of the double shock system, the flow field of the rotor inlet plane was extracted from the L2F measurements. In Figure 15, the absolute Mach number at three axial positions is shown. The first plane was located at a constant axial position about $30 \mathrm{~mm}$ upstream of the leading edge (position 1). The following two positions were taken relative to Leading Edge: $-5 \mathrm{~mm}$ upstream and $1 \mathrm{~mm}$ upstream. It was observed that the velocity level increased due to the endwall's contour. However, the maximum Mach numbers moved toward the hub as the flow approached LE. At $60 \%$ channel height,
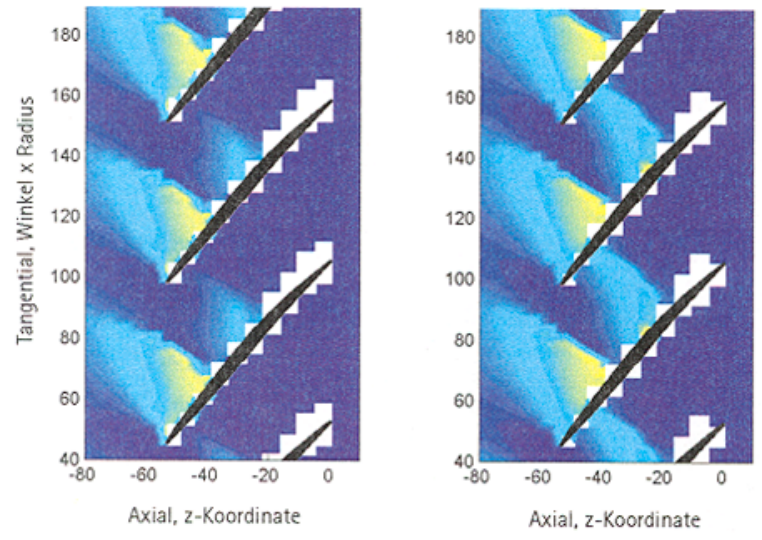

FIGURE 11

Rotor passage at $40 \%$ annulus.

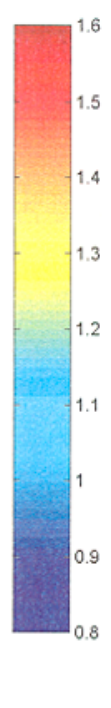

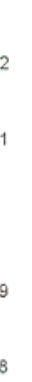

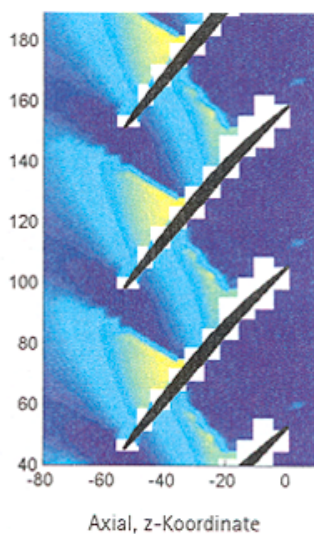



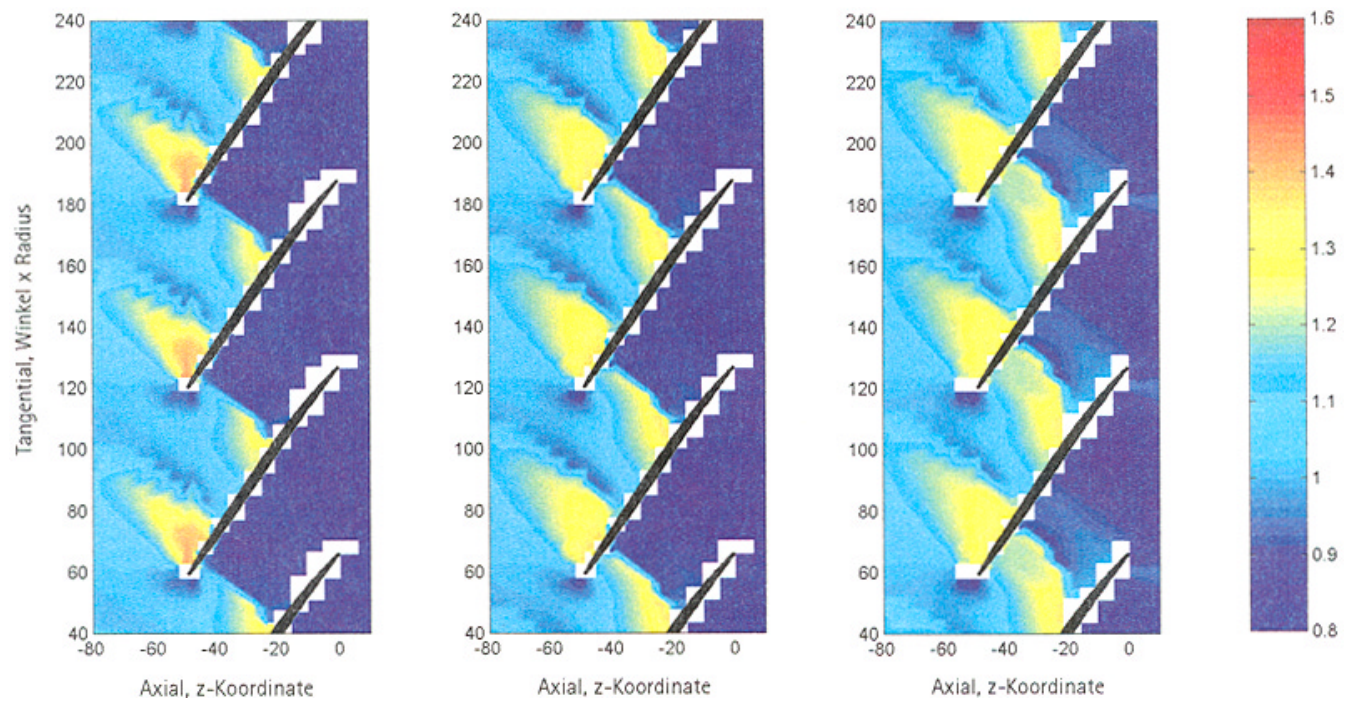

FIGURE 12

Rotor passage at $60 \%$ annulus.

where the double shock system is most clearly visible, the blade experienced the maximum absolute inlet Mach number.

\section{CONCLUSIONS}

Based on the experimental data described here, the aerodynamic characteristics of Rotor No. 2 can be determined. The double shock system on the blade's suction side was found exactly as predicted by the RANS calculations (Blaha et al., 2000). It must be taken into account that the defects in performance and efficiency in comparison to Rotor No. 1 were related in part to the constraints imposed by the CFRP. The application of aft sweep and lean could otherwise have led to more promising blading (see Part II).

Another reason for the unexpected defect in performance was believed to have been caused by the inability of the inviscid three-dimensional CFD code that was used in the design process so as to predict correctly the shift in the mass flow toward the hub as a result of aft sweep. This led to incorrect assumptions about the incidence angles of all blade sections.

The blade sections in the regions with large mass-flow surpluses suffered the most in performance. Toward the casing, work input seemed fine and local efficiency levels were also acceptable. However, below a $60 \%$ span, the blades experienced far
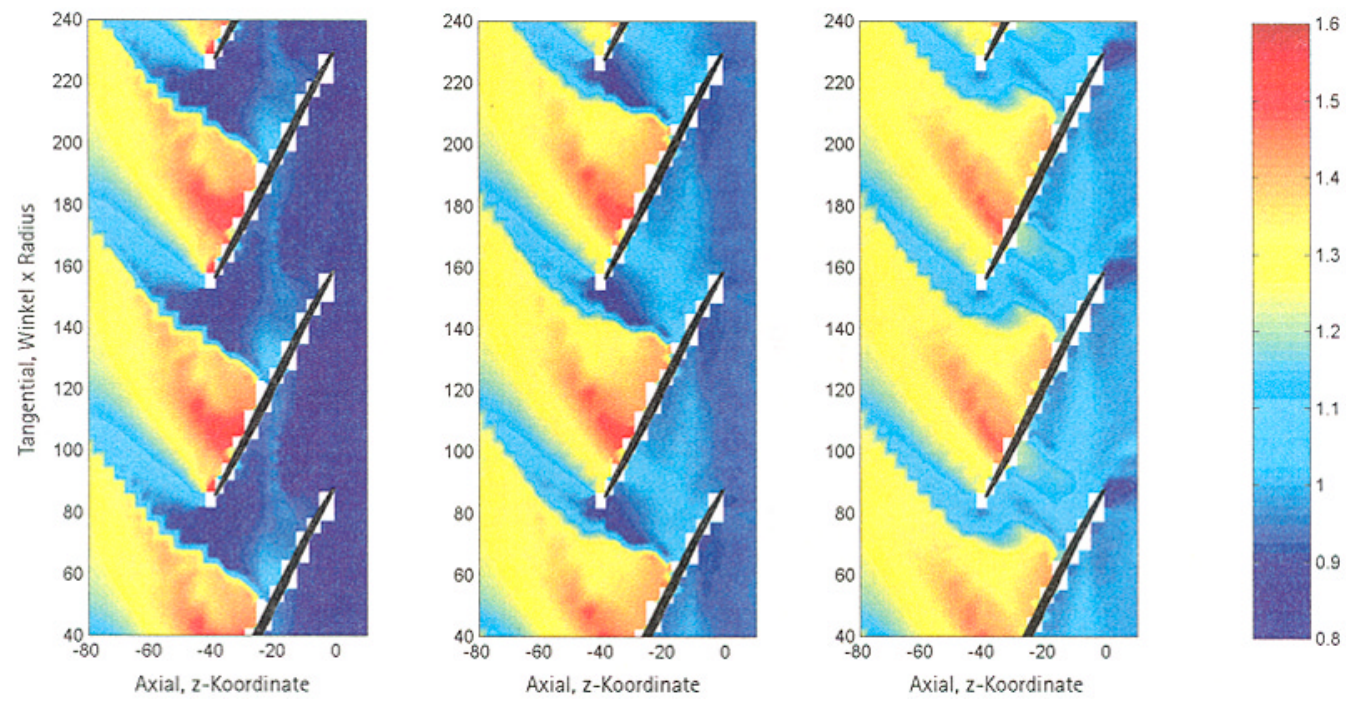

FIGURE 13

Rotor passage at $90 \%$ annulus. 


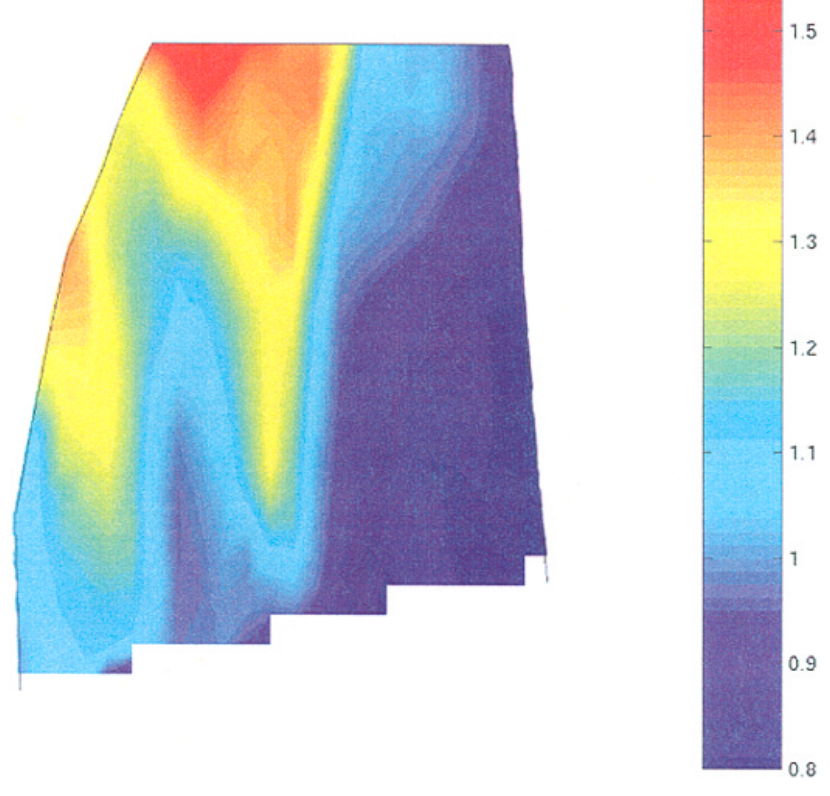

FIGURE 14

Wear suction side at $16 \mathrm{~kg} / \mathrm{s}$.

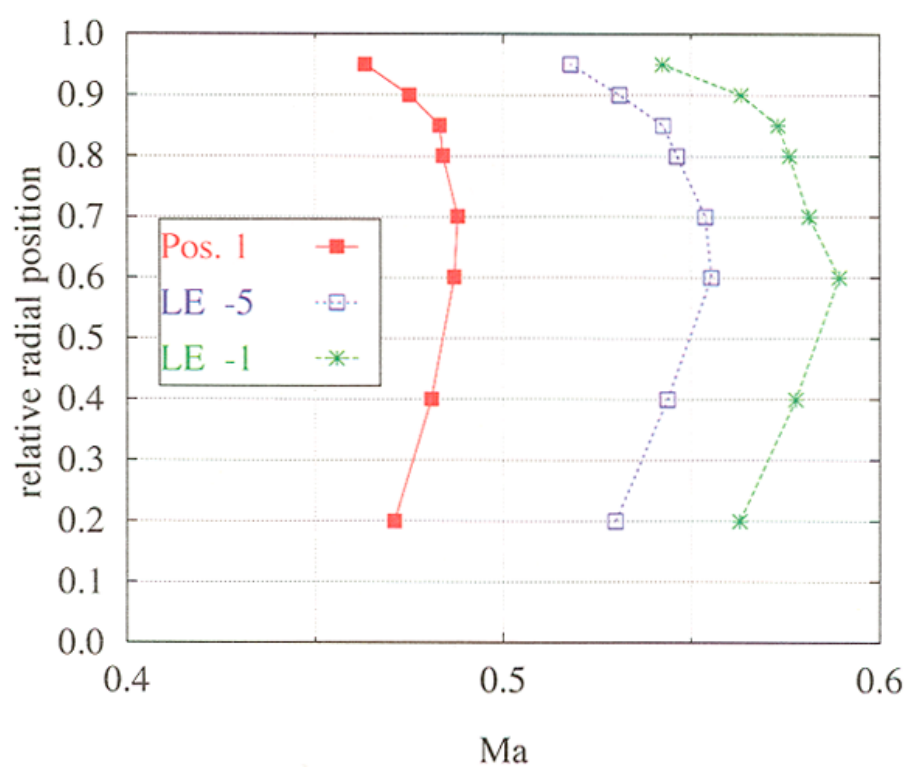

FIGURE 15

Rotor inlet conditions. too negative incidence, and the resulting compression was rather unsatisfying. These problems were at lower mass flow because incidence angles probably shifted toward the design levels.

Rotor No. 2 remains an object of intense interest because its behavior around the stability line is very remarkable and also unexpected. Experimental investigation of these phenomena can be found in Part IV of this article.

The authors believe that Rotor No. 2 will prove very useful in understanding the workings of sweep and lean and will help to validate design systems for an even wider envelope of blade concepts.

\section{REFERENCES}

Blaha, C., Hennecke, D. K., Fritsch, G., Hoeger, M., and Beversdorff, M. 1997. Laser-2-focus measurements in a transonic compressor blisk-rotor and comparison with 3D numerical solutions. Proceedings of the 13th International Symposium on Air-Breathing Engines (ISABE). ISABE Paper 97-7069. Chattanooga, TN: ISABE.

Blaha, C., Kablitz, S., Hennecke, D., Schmidt-Eisenlohr, U., Pirker, K., and Haselhoff, S. 2000. Numerical investigation of the flow in an aft-swept transonic compressor rotor. Proceedings of the ASME Turboexpo 2000, Paper 2000-GT-04090. Munich, Germany: ASME.

Denton, J. D., and Xu, L. 1999. Exploitation of 3D flow in turbomachinery. In Van den Braembusche, R. A., ed. Turbomachinery Blade Design Systems, Lecture Series, 1999-02, Rhode-SaintGenese, Belgium. von Karman Institute for Fluid Dynamics.

Hah, C., Puterbaugh, S. L., and Wadia, A. R. 1998. Control of shock structure and secondary flow field inside transonic compressor rotors through aerodynamic sweep. ASME Paper 98-GT-561. Stockholm, Sweden: ASME.

Saravanamuttoo, H. I. H. 1990. Recommended practices for measurement of gas path pressures and temperatures for performance assessment of aircraft turbine engines and components. AGARD Advisory Report 245. NeuillySurSeine, France: AGARD.

Schulze, G., Blaha, C., Hennecke, D. K., and Henne, J. M. 1995. The performance of a new axial single-stage transonic compressor. Proceedings of the 12th International Symposium on Air-Breathing Engines (ISABE). ISABE Paper 95-7072. Melbourne, Australia: ISABE.

Wadia, A. R., Szucs, P. N., and Crall, D. W. 1998. Inner workings of aerodynamic sweep. ASME Journal of Turbomachinery 120:671.

Zielinski, M., and Ziller, G. 2000. Noncontact vibration measurements on compressor rotor blades. Measurement Science and Technology 11:847. 

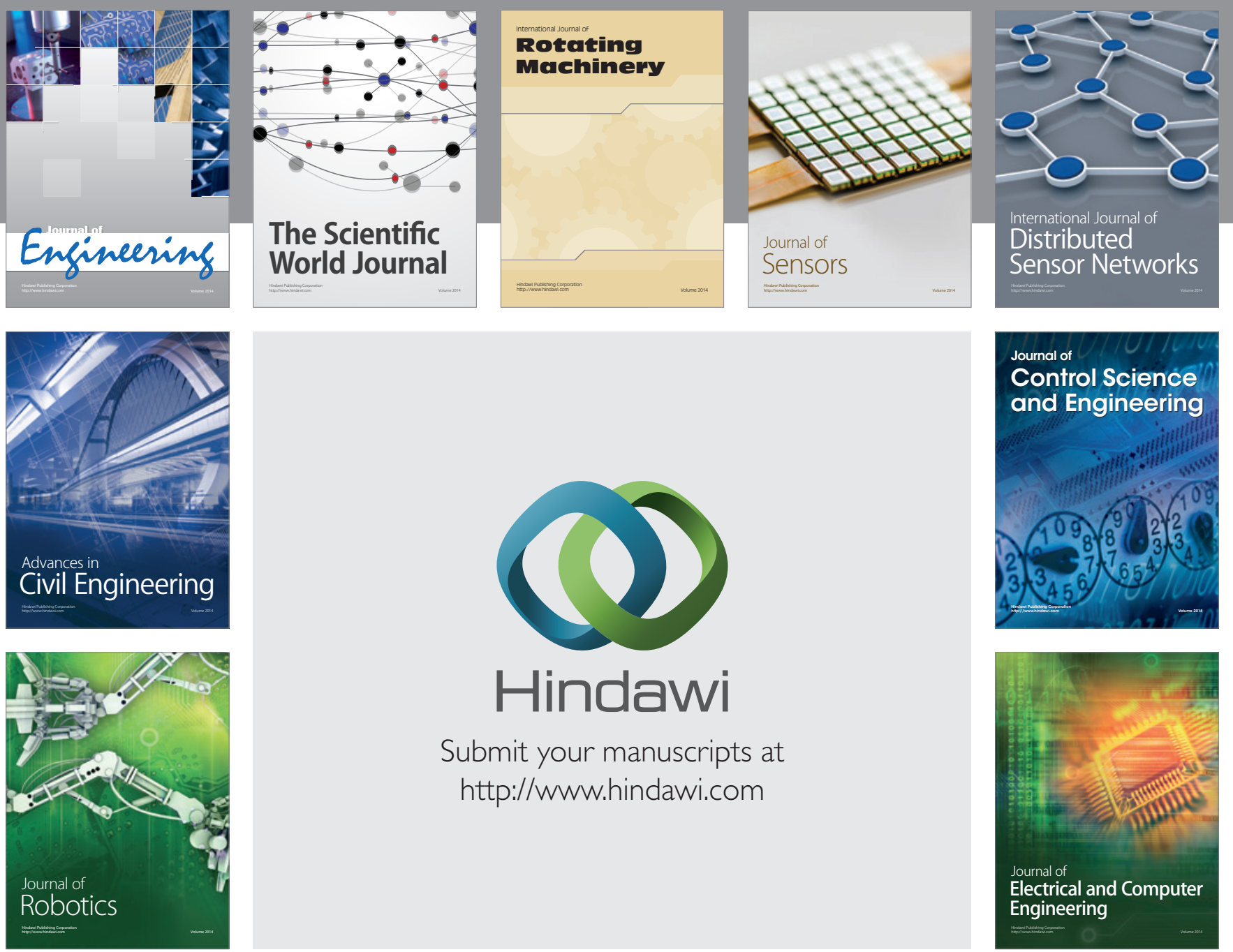

Submit your manuscripts at

http://www.hindawi.com
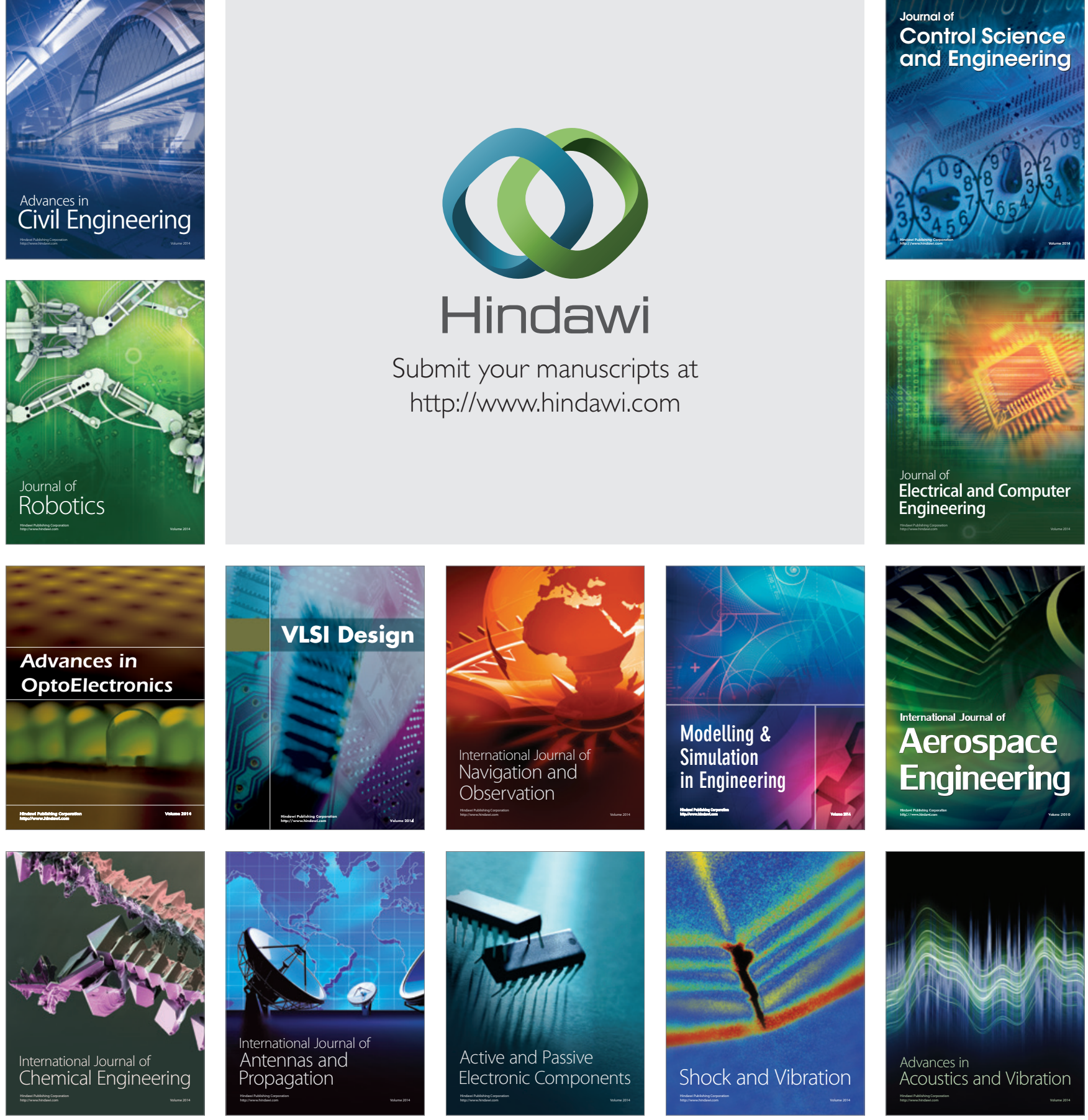